\title{
İmmun checkpoint inhibitörleri ilişkili bağ dokusu hastalıkları
}

\section{Immune checkpoint inhibitors related connective tissue diseases}

\author{
Ayten Yazıcı \\ Kocaeli Üniversitesi Kocaeli Tıp Fakültesi, İç Hastalıkları Anabilim Dalı, Romatoloji Bilim Dalı
}

\section{Öz}

İmmün checkpoint inhibitörleri kanser tedavisinde kullanılan ve kullanımı gün geçtikçe artan ilaçlardır. Bu ilaçlarla hemen her organa ait immün ilişkili yan etkiler bildirilmiştir. Hepatit, kolit, pnömoni, döküntü, tiroidit, hipofizit en sık görülenlerdir. İmmün ilişkili yan etkiler genelde hafif-orta şiddette olup sıklığı \%90'ının üzerinde bildirilmiştir. Romatolojik yan etkiler diğerlerine göre daha az bildirilmiş olmakla birlikte bu yan etkilerin gerçek sıklığı tam olarak bilinmemektedir. İmmün checkpoint inhibitörleri ile en sık bildirilen romatolojik yan etki artralji ve artrittir. Bunun dışında miyozit, sikka sendromu, skleroderma ve sarkoidoz ile ilişkili olgu bildirimleri de mevcuttur. Romatolojik yan etkiler konusunda farkındalığın artması bu olguların erken tanınması ve tedavisi açısından önemlidir.

Anahtar Sözcükler: İmmün checkpoint inhibitörleri, inflamatuvar artrit, sikka sendromu, miyozit, skleroderma.

\begin{abstract}
Immune checkpoint inhibitors are drugs that used in cancer treatment and increased in the use day by day. Immunerelated adverse events of almost any organs are reported with these drugs. Hepatitis, colitis, pneumonitis, rash, thyroiditis, hypophysitis are the most common. Immune-related adverse events are generally mild to moderate, with a frequency greater than 90\%. Although the rheumatologic adverse events are reported less than others, the true incidence of these adverse events is not fully known. Arthralgia and arthritis are the most commonly reported rheumatic immune-related adverse events in immune checkpoint inhibitors. In addition, there are case reports related to myositis, sikka syndrome, scleroderma and sarcoidosis. Increased awareness of rheumatic adverse events is important for early diagnosis and treatment of these cases.
\end{abstract}

Keywords: Immune checkpoint inhibitors, inflammatory arthritis, sicca syndrome, myositis, scleroderma.

\section{Giriş}

İmmün checkpoint inhibitörleri (İCi) son dönemde başta metastatik melanom ve küçük hücre dışı akciğer kanserleri olmak üzere kanser tedavisinde başarı ile kullanılan ve gün geçtikçe kullanımı artan ilaçlardır. Bu ilaçlar direkt tümör hücresini öldürmek yerine $T$ lenfositlerin tümöre cevabını engelleyen düzenleyici yolakları inhibe ederler. Böylece tümör sitotoksik T hücrelerinin hedefi haline gelmektedir. Sağlıklı bireyde normal dokunun hasarlanmasını önleyen self toleransa katkıda bulunan immün checkpointleri hedef alan bu ilaçlar başlıca iki kostimülatör yolak üzerinden etki etmektedir. Sitotoksik T lenfosit ilişkili antijen (CTLA) 4 ve programlanmış hücre ölüm proteini (PD)-1 veya onun ligandına bağlanarak etki gösteren bu ilaçlar tek başına veya kombinasyon halinde kullanılmaktadır (1).

Yazışma Adresi: Ayten Yazıcı

Kocaeli Üniversitesi Kocaeli Tıp Fakültesi, İç Hastalıkları Anabilim Dalı, Romatoloji Bilim Dalı

E-mail: burakdefy@hotmail.com
Bu ilaçların kullanımı sırasında çeşitli organlarda immün ilişkili pek çok yan etki bildirilmiştir. Gastrointestinal sistem (kolit), karaciğer, akciğer (pnömoni), deri (raş, kaşıntı, vitiligo) ve tiroid, hipofiz gibi endokrin bezlerle ilişkili yan etkiler bunlardan bazılarıdır (2). Klinik çalışmalarda \%90'ın üzerinde immün ilişkili yan etki bildirilmiş olup bunların yaklaşı \%75'i CTLA-1 inhibitörleri ile bildirilmiştir ve çoğu hafif-orta yan etkilerdir. Ciddi yan etkilere bakıldığında CTLA-4 inhibitörleri ile hastaların \%43'ünden fazlasında, PD-1 veya PD-1 ligand inhibitörleri ile ise \%20'den azında 3. derece ve daha şiddetli yan etkiler bildirilmiştir. Fatal yan etkiler ise $\% 2$ civarında görülmüştür $(1,3)$

İmmün ilişkili yan etkiler genel olarak her kanser tipinde ve tüm ici ile bildirilse de bazı yan etkiler ilaca spesifik gibi görünmektedir. Mesela pnömoni anti-PD-1 inhibitörlerinin kullanımı sırasında görülürken hipofizit bir CTLA-4 inhibitörü olan ipilimumabla bildirilmiştir. Ayrıca bu yan etkilerin çoğu önceden var olan bir otoimmün hastalığın alevlenmesi veya relapsı şeklindedir; yeni gelişen otoimmün hastalıklar daha az gibi görünmektedir $(1,4)$. İmmün ilişkili yan etkilerin ortaya çıkma zamanı değişken olup ilk doz sonrası ortaya çıkabileceği gibi aylar sonra da gelişebilmektedir. Mesela cilt bulguları ve 
kolit erken dönemde ortaya çıkarken pnömoni ve endokrinopatiler daha geç dönemde görülmektedir (3).

\section{Patogenetik Mekanizma}

ICl'lerle gelişen immün ilişkili yan etkilerin mekanizması tam olarak bilinmemektedir. Genel olarak dört mekanizma üzerinde durulmaktadır. İlki immün checkpointlerin nötralize edilmesi sonucu ortaya çıkan genel immün sistem aktivasyonudur ve buna örnek olarak polimiyaljia romatika gösterilmektedir. Bir diğer mekanizma ise antikor-aracılı sitotoksisite ile İcl'lerin doğrudan hedef dışı etkileridir; tümör dışında başka dokularda eksprese olan antijenlere bağlanarak, mesela hipofiz epitelyum hücresinde eksprese olan CTLA-4'e bağlanarak hipofizit gibi antikora aracılı doku hasarlarına neden olabilmektedirler. Ayrıca $\mathrm{T}$ hücre aracılı bağışıklığın hedef dışı etkileri de bu yan etkilerin gelişiminden sorumlu olabilir, buna örnek olarak da miyokardit ve pnömoni gelişimi gösterilmektedir. Bunların yanında önceden var olan ve asemptomatik olan bir otoimmünitenin aşikâr hale gelmesi de söz konusu olabilir. Çok iyi bilindiği gibi anti-sitrüline protein antikorları (ACPA) romatoid artrit (RA) tanısı konmadan çok önce pozitif olabilmektedir. Böyle bir durumda bu ilaçlar otoimmüniteyi tetikleyebilir ve romatoid artrit tablosu gelişebilir (1).

\section{Bağ Dokusu Hastalıkları Benzeri Yan Etkiler}

iCl'nin kullanımının artması ile birlikte romatolojik yan etkiler de daha önemli hale gelmektedir. Klinik çalışmalarda diğer immün ilişkili yan etkiler kadar sık romatolojik yan etkilerin bildirilmediği görülmektedir. Yazarlar bunun aslında gerçeği yansıtmadığını, mevcut olandan daha az bildirilmiş olduğunu, tanı koymadaki sorunlar nedeni ile bu yan etkilerin gözden kaçırıldığını vurgulamaktadır. Çalışmalarda yan etkiler kodlanırken kas iskelet sistemi ile ilgili pek çok kodun kullanılması bu sorunlardan sadece biridir; mesela artrit için artralji, artrit, eklemde şişlik, eklemde ağrı şeklinde pek çok kod kullanılmaktadır. Ayrıca birçok romatolojik yan etki ciddi olmayıp hastaneye yatışı gerektirmediği için bildirilmemiş olabilmekte, hastaların çoğu romatoloğa yönlendirilmemekte, ayrıca romatolojik yan etkiler diğer immün yan etkilere göre daha geç ortaya çıkabilmektedir. Bu gibi nedenlerle romatolojik yan etkilerin sıklığı ile ilgili verilerin yetersiz olduğu düşünülmedir (1).

Hemen hemen tüm romatolojik hastalıklar ile ilgili yan etki bildirilmiş olup bu yan etkilerin mevcut hastalığın aktifleşmesi, alevlenmesi şeklinde ya da yeni hastalık gelişimi şeklinde olduğu belirtilmiştir. Bu konu ile ilgili çok sınırı literatür verisi olmakla birlikte, kas iskelet sistemi ile ilişkili şikayetlerin yanı sıra polimiyaljia romatika, vaskülitler, küçük ve büyük eklemlerde inflamatuvar artritler, sikka sendromu, miyozitler ile ilgili olgu bildirimleri mevcuttur (2).
Romatolojik yan etkilerin gerçek sıklığı bilinmemekle birlikte klinik çalışmalarda en sık bildirilen romatolojik yan etki artralji ve artrittir (3). Kostine ve ark.'nın (5) 524 olgu içeren serilerinde romatolojik yan etki sıklığı \%6.6 olarak bildirilmekte ve bunların yarısından çoğunun (\%3.8) da inflamatuvar artrit olduğu belirtilmektedir. Yine başka bir retrospektif çalışmada çoğu inflamatuvar artrit (\%85) olmak üzere romatolojik yan etki sıklığı \%3.5 (14/400 hasta) olarak bildirilmiştir (6).

Artralji ve Inflamatuvar artrit: Klinik çalışmalarda en sık bildirilen yan etki artralji olup sıklık farklı çalışmalarda \%1-43 arasında bildirilmektedir. İnflamatuvar artritin ise sıklığı tam olarak bilinmemektedir, bunun bir nedeni de romatologlar tarafından inflamatuvar artritin konfirme edildiği gözlemsel geniş kohortların olmamasıdır (3).

PD-1 inhibitörlerinden nivolumab ile \%5-16, pembrolizumab ile \%9-20 oranında artralji bildirilmiş olup benzer oranlar CTLA-4 inhibitörü olan ipilimumab ile de bildirilmiştir. $\mathrm{Bu}$ ajanların kombinasyon tedavileri sırasında da en sık görülen yan etki artralji olup sıklığı \%10.5 olarak bildirilmiştir. ICl'ler başka bir grup ile mesela peptid aşıları ile kombine edildiğinde ise yan etki sıklığının arttığı, artralji oranının \%43 gibi yüksek değerlere ulaştığı görülmüştür (Tablo-1) $(1,3,4,7,8)$. Artraljinin genellikle simetrik olarak en sık omuz, diz gibi büyük eklemlerde geliştiği ve median 100. günde başladığı (7-780 gün) gözlenmiştir (8).

Tablo-1. İmmün checkpoint inhibitörleri ile ilişkili romatolojik

\begin{tabular}{lll}
\multicolumn{2}{c}{ yan etkiler ve sıklıkları (7). } & \\
\hline Ajan & Yan etki & Sıklık \\
\hline CTLA-4 inhibitörü & Artralji ve artrit & $\% 5-16$ \\
(ipilimumab) & Miyalji & $\% 2-18$ \\
& Sikka sendromu & $\% 3-4$ \\
& Kuru göz & $\% 3-4$ \\
& Ağız kuruluğu & $\% 7$ \\
\hline PD-1 inhibitörü & Artralji ve artrit & $\% 5-16$ \\
(nivolumab) & Miyalji & $\% 2-18$ \\
& Sikka sendromu & $\% 3-11$ \\
& Ağız kuruluğu & $\% 3-11$ \\
\hline Kombine tedavi & Artralji ve artrit & $\% 10.5$ \\
& Miyalji & $\% 1$ \\
& Sikka sendromu & $\% 3-4$ \\
& Ağız kuruluğu & $\% 3-4$ \\
\hline
\end{tabular}

İflamatuvar artrit sıklığı tam olarak bilinmemekle birlikte \%1-7 arasında bildirilmiştir (9). Klinik olarak hem büyük hem de küçük eklemlerde daha çok poliartiküler olmak üzere oligoartiküler ve poliartiküler tutulum olduğu görülmüştür. Az bir hasta grubunda ise reaktif artrit triadı (eklem tutulumunun yanında üretrit ve konjonktivit) bildirilmiştir (1). Fransız veritabanında PD-1 inhibitörü kullananların \%0.7'sinde seronegatif artrit, \%0.2'sinde RA, \%0.2'sinde psoriatik artrit geliştiği, PD-1 ve CTLA-4 inhibitörü kombinasyonunu alanların ise $\% 2.5$ 'inde seronegatif artrit geliştiği bildirilmiştir $(1,10)$. Bildirilen olguların çoğu sadece nonsteroid antiinflamatuvar ilaçlar (NSAii) veya düşük doz steroid tedavisi gerektiren hafif tutulumlu olgular olup hastaların çoğu anti siklik sitrüline 
peptid (CCP) ve romatoid faktör (RF) negatif olarak bildirilmiştir (Tablo 2). Küçük bir subgrupta seropozitiflik bildirilmiş; ama bu grubun bir kısmında tedavi öncesinde de seropozitiflik olduğu belirtilmiştir $(1,3)$. Bir çalışmada inflamatuvar artritin başlama zamanı ile tanı konması arasında geçen süreye bakılmış ve ilaç başlandıktan yaklaşık 5 ay sonra artritin başladığı, tanının ise ortalama 5.2 ay gecikme (en uzun gecikme süresi 26 ay) ile konduğu belirtilmiştir (11). İnflamatuvar artritin ortalama başlama zamanı genelde ilk uygulamadan sonraki 100. gün olarak bildirilmekte olup 2 yıl gibi daha geç dönemde de başladığı bildirilen olgular mevcuttur $(1,3)$.

Inflamatuvar miyopati: Klinik çalışmalarda miyozit inflamatuvar artritten daha az bildirilmiştir. İpilimumab ve nivolumab kullanımı sırasında \%2-18 oranında miyalji bildirilirken tek veya kombine ipilumumab kullanımında $\% 1$, peptid aşılarla kombine nivolumab kullanımında ise \%12 oranında kas güçsüzlüğü gözlenmiştir (Tablo 1) $(1,7)$. Miyozit ise daha az gözlenmiş olup retrospektif bir çalışmada PD-1 inhibitörleri ile \%0.8 oranında miyozit bildirilmiştir (12). Bildirilen miyozitler yeni başlangıçlı olgular olup çoğunlukla polimiyozit şeklinde prezente olmuş, dermatomiyozit ise çok nadiren bildirilmiştir. Bu hastalarda kreatin kinazın 10 ve daha fazla arttığı, tipik olarak proksimal kasların etkilendiği bildirilmiştir (Tablo 2). Fakat hastaların bir bölümünde distal kasların ve solunum kaslarının tutulduğu, solunum kas tutulumuna bağlı mortalitenin geliştiği gözlenmiştir. Ayrıca bir grup hastada antikor pozitifliği ile birlikte miyastenia da bildirilmiştir (1).

Sikka sendromu: Göz kuruluğu olsun olmasın ağız kuruluğu íci tedavisi alan hastalarda gelişebilmektedir. $\mathrm{Bu}$ bulguların akut olarak ortaya çıktığı ve hastanın hayat kalitesini önemli ölçüde bozduğu belirtilmiştir (1). Klinik çalışmalarda nivolumab ile (doza bağlı olarak) \%310 , pembrolizumab vs ipilimumab ile \%4-7 oranında ağız kuruluğu bildirilmiştir. Peptid aşıları ile nivolumab kombinasyon tedavisinde ise \%24 oranında sikka bulguları bildirilmiştir. Göz kuruluğu ise ipilimumab ile \%3-4 olarak bildirilmiş ama şiddeti ve tedavisi hakkında bilgi verilmemiştir (Tablo-1) (3,7). Bu olgularda klasik sikka sendromundan farklı olarak genellikle anti-Ro / anti-La negatif saptanmış ve eş zamanlı parotite rastlanmamıştır (Tablo-2) (1).

Diğer sendromlar: Pembrolizumab ile biri difüz, diğeri ise sınırlı 2 skleroderma olgusu bildirilmiş. Ayrıca nivolumab ve ipilimumab ile bir hastada kritik dijital iskemi, pembrolizumab ile de bir eozinofilik fasiit olgusu bildirilmiştir $(1,3)$.

İilimumab ile dsDNA antikoru pozitif olan bir lupus nefriti bildirilmiş olup bu olguda sistemik lupus eritematozusa ait başka bir kliniğe rastlanmadığı belirtilmiştir $(1,3)$. Nefrotik düzeyde proteinürisi olan bu olguda böbrek biyopsisi ile immünfloresanla mezenkimal alanda $\operatorname{lgM}$, IgG, C3 ve C1q birikimi gösterilmiş ve ilaç kesilince de anti-dsDNA'nın negatifleştiği bildirilmiştir (3).

Hem PD-1 hem de CTLA-4 inhibitörleri ile akciğerde, ciltte ve lenf bezlerinde granülomatoz tutulumlu sarkoidoz olguları da mevcuttur (1). Yine ipilimumab ile (dacarbazin ile kombine verilmiş) otoimmün vaskülit ve dev hücreli arterit gelişen birer olgu bildirilmiştir $(3,7)$.

icl'lerin kullanımı sırasında gelişen yan etkilerin fenotipi tam olarak aydınlatılamamıştır. Bu nedenle bu yan etkilerin otoimmün bağ dokusu hastalıkları ile olan benzerlik ve farklılıklarının tanımlanması (Tablo 2), bu yan etkiler konusunda farkındalığın artması tanı açısından faydalı olacaktır. Romatolojik bir yan etkiden şüphelenildiğinde bir romatolog tarafından fizik muayene, laboratuvar testleri, görüntüleme ve diğer özel testleri de içeren tam bir değerlendirme yapılması önerilmektedir. Romatolog ve onkologların iş birliği bu yan etkilerin erken tanınması ve tedavisi açısından önemlidir.

Tablo-2. İmmün checkpoint inhibitörleri ile ilişkili romatolojik yan etkiler otoimmün romatolojik hastalıklar arasındaki farklar ve benzerlikler (1).

\begin{tabular}{|c|c|c|c|}
\hline Romatolojik yan etki & Romatolojik hastalık & Benzerlikler & Farklılıklar \\
\hline \multirow[b]{2}{*}{ İnflamatuvar artrit } & Romatoid artrit & $\begin{array}{l}\text { *Eroziv hastalık } \\
\text { *Benzer eklem tutulumu (MKF, PiF, } \\
\text { el bileği, diz) }\end{array}$ & $\begin{array}{l}\text { *Erken erozyon } \\
{ }^{*} \text { RF, CCP }(-) \\
{ }^{*} \text { Kadın hakimiyeti yok } \\
\text { *Erken dönemde tendon } \\
\text { tutulumu belirgin }\end{array}$ \\
\hline & $\begin{array}{l}\text { Spondiloartropati } \\
\text { Psöriatik artrit }\end{array}$ & $\begin{array}{l}\text { *Benzer SpA özellikleri } \\
\text { (İnflamatuvar bel ağrısı, } \\
\text { entezit, daktilit..) } \\
\text { *Reaktif artrit benzeri } \\
\text { (üretrit, konjonktivit, } \\
\text { oligoartit) } \\
\end{array}$ & $\begin{array}{l}\text { *Psoriasis nadir } \\
\text { *HLA B27 (+)'liği yok } \\
\text { *Erken erozyon }\end{array}$ \\
\hline İnflamatuvar miyozit & $\begin{array}{l}\text { Dermatomiyozit } \\
\text { Polimiyozit }\end{array}$ & $\begin{array}{l}\text { *Kreatin kinaz yüksek } \\
(10-100 \text { kat }) \\
\text { *Biyopsi benzer }\end{array}$ & $\begin{array}{l}\text { *Tipik raş yok } \\
\text { *iviG yanıtı az }\end{array}$ \\
\hline Sikka sendromu & Sjögren sendromu & $\begin{array}{l}\text { *Ağız ve göz kuruluğu } \\
\text { *Siyalagoglara yanıt }\end{array}$ & $\begin{array}{l}\text { *Anti Ro-Anti La nadir } \\
{ }^{*} \text { Parotitis nadir }\end{array}$ \\
\hline
\end{tabular}




\section{Kaynaklar}

1. Calabrese L, Calabrese C, Cappelli LC. Rheumatic immune-related adverse events from cancer immunotherapy. Nat Rev Rheumatol 2018;14(10):569-79.

2. Pisetsky DS. Effects of immune checkpoint inhibitors on B cell: relationship to immune-related adverse events. Ann Rheum Dis 2018;77(6):795-6.

3. Cappelli LC, Shah AA, Bingham CO 3rd. Immune-related adverse effects of cancer immunotherapy-implications for rheumatology. Rheum Dis Clin North Am 2017;43(1):65-78.

4. Belkhir R, Burel SL, Dunogeant L, et al. Rheumatoid arthritis and polymyalgia rheumatica occuring after immune checkpoint inhibitor treatment. Ann Rheum Dis 2017;76(10):1747-50.

5. Kostine M, Rouxel L, Barnetche T, et al. Rheumatic disorders associated with immune checkpoint inhibitors in patients with cancer - clinical aspects and relationship with tumour response: a single-centre prospective cohort study. Ann Rheum Dis 2017;77(3):393-8.

6. Lidar M, Giat E, Garelick D, et al. Rheumatic manifestations among cancer patients with immune checkpoint inhibitors. Autoimmun Rev 2018;17(3):284-9.

7. Tocut M, Brenner R, Znadman-Goddard. Autoimmune phenomena and disease in cancer patients treated with immune checkpoint inhibitors. Autoimmun Rev 2018;17(6):610-6.

8. Buder-Bakhaya K, Benesova K, Schulz C, et al. Characterization of arthralgia induced by PD-1 antibody treatment in patients with metastasized cutaneous malignancies. Cancer Immunol Immunother 2018;67(2):175-182.

9. Naidoo J, Cappelli LC, Forde PM, et al. Inflammatory arthritis: A newly recognized adverse event of immune checkpoint blockade. Oncologist 20017;22(6):627-30.

10. Le Burel S, Champiat S, Mateus C, et al. Prevalence of immune-related systemic adverse events in patients treated with antiprogrammed cell death 1/anti-programmed cell death-ligand 1 agents: A single-centre pharmacovigilance database analysis. Eur J Cancer 2017;82:34-44.

11. Cappelli LC, Brahmer JR, Forde PM, et al. Clinical presentation of immune checkpoint inhibitor-induced inflammatory arthritis differ by immunotherapy regiment. Semin Arthritis Rheum 2018;48(3):553-7.

12. Liewluck T, Kao JC, Mauermann ML. PD-1 inhibitor-associated myopathies: Emerging immune-mediated myopathies. J Immunther 2018;41(4):208-11. 